\title{
Physio - Chemical Nutritional and Sensory Evaluation of Local Quince Fruit of Nomal Village, Gilgit - Baltistan, Pakistan
}

\author{
Nawazish Ali ${ }^{1}$, Yawar Abbas ${ }^{2}$, Attarad Ali $^{3}$, Muhammad Shahnawaz ${ }^{1}$, Naveed Hussain ${ }^{1}$, \\ Altaf Hussain ${ }^{1}$ \\ ${ }^{1}$ Department of Agriculture and Food Technology, Karakoram International University, Gilgit, Pakistan \\ ${ }^{2}$ Department of Earth and Environmental Sciences, Bahria University, Islamabad, Pakistan \\ ${ }^{3}$ Department of Biotechnology, Quaid - i - Azam University, Islamabad, Pakistan

\section{Email address:} \\ amjadmalik747@gmail.com (N. Ali),dr.shahnawaz@kiu.edu.pk (M. Shahnawaz), mellow_786@yahoo.com (A. Hussain), \\ Naveed_kiu@yahoo.com (N. Hussain),yawar_zaid@yahoo.com (Y. Abbas), attarad.ali@kiu.edu.pk (A. Ali)
}

\section{To cite this article:}

Nawazish Ali, Yawar Abbas, Attarad Ali, Muhammad Shahnawaz, Naveed Hussain, Altaf Hussain. Physio - Chemical Nutritional and Sensory Evaluation of Local Quince Fruit of Nomal Village, Gilgit - Baltistan, Pakistan. International Journal of Nutrition and Food Sciences. Vol. 4, No. 6, 2015, pp. 600-608. doi: 10.11648/j.ijnfs.20150406.11

\begin{abstract}
Quince fruit is a late season, non - climacteric fruit and not grown all over the world. Samples were collected from Nomal Village and Physio chemical Analysis were conducted and results of the samples after analysis are Total Soluble Solids (TSS), ash content, sugars (total sugars, reducing and non - reducing), total phenolics and ascorbic acid (12.36 0Brix), (3.36\%), $(9.63 \%),(5.26 \%),(4.36 \%),(15.70 \mathrm{mg} \mathrm{GAE} / 100 \mathrm{~g})$, and $(23.66 \mathrm{mg} / 100 \mathrm{~g}$ Malic acid) respectively, were found high in sweet variety of Quince fruit as compared to sour variety (10.73 0Brix), (2.53\%), (9.00\%), (5.05\%), (4.00\%), and (7.70 mg GAE $/ 100 \mathrm{~g})$ respectively and $(20.33 \mathrm{mg} / 100 \mathrm{~g}$ Malic acid) respectively, of which $\mathrm{pH}$, moisture content, antioxidants and Titratable Acidity were statistically same in both varieties of Quince fruit. Physical attributes such as fruit thickness, fruit volume, fruit weight, pulp weight and sphericity $(93.00 \mathrm{~mm}),(328.53 \mathrm{~cm} 3),(335.00 \mathrm{~g})(331.00 \mathrm{~g})$ and $(122.20 \%)$ respectively were recorded higher in sweet variety of Quince fruit compared to sour variety of Quince fruit (89.60), (285.40 cm3), $(293.33 \mathrm{~g}),(289.00 \mathrm{~g})$ and $(103 \%)$ respectively, Geometric mean diameter and length $(83.33 \mathrm{~mm})$, and $(96.66 \mathrm{~mm})$ respectively were found high in sweet variety of Quince fruit compared to sour variety of Quince $(73.33 \mathrm{~mm})$, and $(86.66 \mathrm{~mm})$ respectively, of which edible portion, seed and peel were statistically same in both varieties. Higher scores were assigned for taste, color, flavor and overall acceptability (7.333), (7.400), (8.266) and (8.366) respectively in sweet variety of Quince fruit as compared to sour variety of Quince fruit (6.233), (7.233), (7.266) and (7.166) respectively. However color scores of both varieties were statistically same.
\end{abstract}

Keywords: Physio Chemical, Quince Fruit, Percentage, Nutrients, Evaluation

\section{Introduction}

Quinces belong to the Rosaceae family and the sub family Maloideae, scientific name (Cydonia oblonga miller) has many seeds and is a pome fruit (Rasoulzadegan, 1991). It is originated from Middle East and throughout the Mediterranean region. Romans and Greeks, for their aromatic fruit and gorgeous pink flowers grew Quince. Turkey is considered as the largest Quince growing country (Marina et al., 2010). Greeks and Romans grew the Quince for its aromatic fruit and gorgeous pink flowers. Nowadays, Turkey is the leading country of Quince production in the world (Marina et al., 2010). From the last ten years (1998 - 2008) the average production of Quince globally is estimated at 510, 000 tones (FAO, 2010). Worldwide, there are more than 70 genotypes of Quince some of them are Botermo, Portugal, Van Deman, Morova, Meeh, Orage, Spahan, Ekmek and Pineapple (Madi et al., 1996). The total production of Quince throughout the world is 335, 000 MT. Turkey is the largest Quince producer and contributes $25 \%$ alone of world production. However, Zargari claims that Iran supplies about $75 \%$ of the world production (Zargari et al., 1986). Morocco, China and Argentina producing less than $10 \%$ of world production. USA 
produces Quince in very minor amount growing Quince only in 100 hectors (McCabe, 1996). Quince and Apple are similar fruit but Quince differs as it has many seeds in each carpel. The fruits are globular, oblong or pear shaped form of rich yellow or orange colored when ripe of an austere taste and emitting a peculiar and pleasant smell (Wallis, 2005). Quinces are used nowadays in industries for the manufacture of marmalades, cakes, jams and jellies (Silva, 2002). Quince has the important nutritional and flavor composition more than many fruits. Vitamin C content of Quince is nearly two - times higher than in apple (Biro and Lindner, 1999). It is an important source of sugars, crude fibers, organic acids and minerals, they are calcium, phosphorus and potassium and it has very low amounts of fat (Sharma et al., 2011; Shinomiya etal 2009; Rodriguez - guisado et al., 2009). The content of pectin in fruits ranged between 1.75 and $3.51 \mathrm{~g} / 100 \mathrm{~g} \mathrm{FW}$, and cultivar Hruskovita accumulated pectin in greatest amount. A medium sized fresh Quince weighing 300g contains, $62.57(\mathrm{~g})$ Nitrogen, 12.95 (g) Phosphorus, 165.87 (g) Potassium, 9.31 (g) Calcium, 4.36 (g) Magnesium, 1.16 (g) Sodium, / (mg/100 g FW) of Asenica variety (Rop et al., 2011). Quince. Quinces are rich in phytic, malic and quinic acids and also in fructose, sorbitol and glucose, which gives them an interesting equilibrium among sourness, astringency and sweetness. (Przemysław et al., 2014 and Hamauzu et al., 2006). Quince fruit are reported comparatively higher amount of antioxidant activity and phenolic concentration (Hamid and Khadijeh, 2014). In many technological processes and in the assessment of the product quality, the volume and density of fruit are very important (Karacali, 1990 and kawamura, 2000). Physico chemical characteristics of the fruits have a significant role in the handling and processing. The engineers, horticulturists and food technologists are very concerned with these characteristics of fruits as together they purse to enhance the suitable handling harvesting and technologies concerned in the processing of fruits (Xie and Zhao, 2004). Different physicochemical characteristics of the fruits like the shape, color, $\mathrm{pH}$, density, size and antioxidant activity, ascorbic acid, titrate able acidity of fruits are very important for the manufacturing of harvesting and processing equipment's and other technologies (Liang et al., 1991). Quince varieties for moisture, fruit dimensions, sphericity, surface area, fruit mass, fruit volume, geometric mean diameter, ash, $\mathrm{pH}$, acidity, vitamin $\mathrm{C}$, colour, total phenolic content, protein, TSS, minerals and antioxidant activity and statistical differences among cultivars were reported (Hamid et al., 2014). (Chenet et al., 2007) analyzed composition of fruits, studied for fatty acids, sugars, organic acids, amino acids, phenolics and minerals and volatile compounds in many fruits. The nature and concentration of these constitutions are accountable for organoleptic features of fruits, from commercial point of view these are very important. (Sharma et al., 2011) and (Silva et al., 2002) studied chemical composition of different varieties of Quince fruit. Such as tannins, crude fibers, total acidity, total sugars, total solids, minerals, like potassium, sodium, calcium, phosphorus and authenticated that Quince contain a high amount of organic acids these are ascorbic acids, citric acids, malic acids, gulatamic acids and aspartic acids.

\section{Material and Methods}

\subsection{Study Area}

Nomal is Village in District Gilgit, Gilgit - Baltistan, Pakistan. It is $25 \mathrm{Km}$ away from Gilgit. The Village is famous for its fertile soil. Majority of the inhabitants of the village is engaged with the agriculture along with the other professions. The Village is famous for its cherry and vegetables. Among the vegetables, Potato is an important cash crop for the farmers. Quince fruit is also grown in all districts of Gilgit - Baltistan however it is mostly found in Nomal valley. unfortunately Information about annual fruit production in Gilgit - Baltistan is not recorded.

\subsection{Sample Collection}

The Quince fruit were harvested at commercially maturity stage and transported to the Food Science and Product Development Institute, National Agriculture Research Center, Islamabad, Pakistan. Fruit, were cleaned and washed to remove all foreign matter such as dirt, dust and were sorted for immature and damaged fruits.

\subsection{Physico - Chemical Analysis}

Following physical and chemical parameters were carried out for each variety of Quince fruit.

\subsection{Chemical Parameters}

\subsubsection{Moisture Content}

The moisture of fruit samples were determined by following the method described by AOAC (1990). In this regard, the sample material were taken in a flat - bottom dish (pre - weighed) and kept overnight in an oven at $100-110^{\circ} \mathrm{C}$ and weighed. The loss in weight was regarded as a measure of moisture content. The following formula was used to calculate the moisture content;

$$
\begin{aligned}
& \text { Moisture (\%) } \\
& =\frac{\text { Wt. of fresh sample }- \text { Wt. of sample after drying }}{\text { Wt. of Sample }} \times 100
\end{aligned}
$$

\subsubsection{Determination of Total Soluble Solids}

Total soluble solids (TSS) of fruit samples were determined as per described by mazumdar and majumder (2003) using Digital - Bench - Refrectometer. Before use, the instrument was cleaned and adjusted to zero at $20{ }^{\circ} \mathrm{C}$ using distilled water. An appropriate quantity of sample was placed on the prism plate of the refrectometer with the help of glass rod and folding back the cover. For each sample, the instrument was calibrated using distilled water. The reading appeared on the screen was directly recorded as total soluble solids (brix)

\subsubsection{Ash Content}

The ash content was determined by incinerating the dried 
sample in Muffle furnace at $500-600^{\circ} \mathrm{C}$ for 5 to 6 hours as described in AOAC (1990). The following formula was used to calculate the ash;

$$
\text { Ash }(\%)=\frac{\text { Wt. of ash }(\mathrm{g})}{\text { Wt. of sample }(\mathrm{g})} \times 100
$$

\subsubsection{Total Sugars}

Total sugar content of different Quince varieties collected from Nomal were determined by Lane and Eynon method as described in AOAC (1990). The following formula was used to calculate the total sugars;

$$
\text { Total Sugars }(\%)=\frac{\text { Factor } \times \text { dilution }}{\text { Titer used } \times \text { sample }} \times 100
$$

\subsubsection{Reducing Sugars}

Reducing sugar content of fruit samples were determined by Lane and Eynon method as described in AOAC (1990). The following formula was used to calculate the reducing sugars;

$$
\text { Reducing Sugars }(\%)=\frac{\text { Factor } \times \text { dilution }}{\text { Titer used } \times \text { sample }} \times 100
$$

\subsubsection{Non - Reducing Sugars}

Non-reducing sugar content of fruit samples was determined by subtracting total sugars from reducing sugars.

\subsection{7. $\mathrm{pH}$}

The $\mathrm{pH}$ values of fruit samples were measured by using $\mathrm{pH}$ meter (Inolab) according to AOAC (2000). The $\mathrm{pH}$ meter was calibrated with buffer solution at $\mathrm{pH} 4$ and $\mathrm{pH} 10$. Sample solution was taken in the beaker and inserted. When the first reading was completed, the electrode was washed with distilled water and dried - up with tissue paper. Similarly, as a continue series, all other samples were determined accordingly.

\subsubsection{Titrate Able Acidity (\% in Terms of Malic Acid)}

Titrate able acidity of fruit samples were determined by following AOAC (2000). Each sample of product was treated with $0.1 \mathrm{NaOH}$ solution using titration kit. Where 3 - 5 drops of phenolphthalein indicator were used. The volume of alkali used was noted and calculated by using the following formula;

Titratable Acidity (\%)

$$
=\frac{1 \times \text { Eq. Wt of acid } \times \text { normality of } \mathrm{NaOH} \times \text { titer }}{10 \times \text { weight of sample }(\mathrm{g})} \times 100
$$

\subsubsection{Ascorbic Acid}

The ascorbic acid content of fruit samples was determined as described by mazumdar and majumder (2003). An amount of $10 \mathrm{ml} / \mathrm{g}$ (juice in $\mathrm{ml}$ ) was taken and made volume up to 100mlwith 3\% metaphosphoric acid (HP03) and filtered. Pipetted $10 \mathrm{ml}$ of filtrate into a conical flask and tittered with the standard dye of a pink end point. The titration reading was calculated by the following formula
Ascorbic Acid $(\mathrm{mg} / 100 \mathrm{~g})$
$=\frac{\text { Titer } \times \text { Dye factor } \times \text { Dilution/volume made up }}{\text { Wt. or vol. of sample }(\mathrm{g})} \times 100$

Dye standardization $5 \mathrm{ml}$ of standard ascorbic acid solution diluted with $5 \mathrm{ml}$ of $3 \%$ metaphosphoric acid (HP03). Titrated with dye solution till pink color persists for 10 seconds. Dye factor was calculated ( $\mathrm{mg}$ of ascorbic acid per $\mathrm{ml}$ of dye) as follows

$$
\text { Dye factor }(D . F)=0.5 / \text { titration }
$$

\subsubsection{Total Phenolics (mg GAE/100g)}

The total phenolic content of fruit sample was measured by using the Foilin - Ciocalteau's as described by Sponas and Wrolstad (1990). Five grams of sample was extracted with 25 $\mathrm{ml}$ methanol by shaking for one hour. The total phenolic content was expressed as Gallic acid equivalents (GAE) in mg per $\mathrm{kg}$ of edible fruit. To $100 \mu \mathrm{L}$ of the sample extract (dilute1: $5(\mathrm{v} / \mathrm{v})$ with methanol) $6 \mathrm{ml}$ of twice distilled water and $500 \mu \mathrm{L}$ of Folin - Ciocalteau's reagent was added. After those samples were kept for 5 minutes at room temperature, $1.5 \mathrm{ml}$ of sodium carbonate $(20 \% \mathrm{w} / \mathrm{v})$ was added. The extract was mixed and allowed to stand for 30 minutes at $40^{\circ} \mathrm{C}$ before measuring the absorbance at $765 \mathrm{~nm}$. A mixture of water and reagent was used as blank. The following formula was used to calculate the total phenolics;

$$
\mathrm{C}=\mathrm{cv} / \mathrm{m}
$$

Where,

$\mathrm{C}=$ Total phenolic content $(\mathrm{mg} \mathrm{GAE} / 100 \mathrm{~g})$

$\mathrm{c}=$ Concentration of Gallic Acid (from concentration curve)

$\mathrm{v}=$ Methanol extract

$\mathrm{m}=$ Weight of plant extract

\subsubsection{Antioxidant Activity}

Antioxidant activity of fruit samples were determined by using a modified version of Brand - William etal (1995). It involves the use of free radical 1.1 - diphenyl - 2 picrylhydrazy (DPPH). A $50 \mu \mathrm{L}$ methanoloic solution of each extract (diluted 1: 6) was placed in test tubes and $200 \mu \mathrm{L}$ of $0.1 \mathrm{mM}$ methanolic solution of DPPH was added and allow reacting in the dark place at room temperature. The decrease in absorbance of DPPH at $517 \mathrm{~nm}$ was measured in 5 minutes intervals until the absorbance stabilized ( 30 minutes). All samples were analyzed in triplicate. The DDPH radical scavenging activity of extracts was expressed \% DPPH scavenging activity by using the following formula;

$\mathrm{DPPH}$ scavenging activity $(\%)=\left[\right.$ (Abs Control ${ }^{\text {姜 }} \mathrm{Abs}$ Sample)/Abs Control] $\times 100$

\subsubsection{Physical Parameters}

Physical characteristics such as fruit weight and pulp weight of samples were determined by a digital electronic balance 
(Inolab. WTW Series, Germany), with $0.001 \mathrm{~g}$ sensitivity, using 12 randomly selected fruits from each variety. Geometric dimensions i.e. length $(\mathrm{L})$, width $(\mathrm{W})$, thickness $(\mathrm{T})$ of fruits were measured by a digital caliper $(0-150 \mathrm{~mm}$, China) with an accuracy of $0.01 \mathrm{~mm}$. Quince fruit volume (V) was measured by liquid displacement method, while surface area (S) was determined according to Mohsenin (1970) and Baryeh (2001) by the following formula:

$$
\mathrm{S}=\pi \mathrm{Dg} 2
$$

Where, $\mathrm{Dg}$ is the Geometric mean diameter of the fruit.

The Geometric mean diameter (Dg) was calculated by using the following equation,

$$
\mathrm{Dg}=(\mathrm{LWT}) 0.333
$$

Where $\mathrm{L}$ is length, $\mathrm{W}$ is width and $\mathrm{T}$ is thickness of the fruit as described by Mohsenin (1970).

Sphericity of the fruit was determined by the following formula

$$
\Phi=(\mathrm{Dg} / \mathrm{L}) \times 100
$$

\subsubsection{Determination of Seed (\%)}

Quince seed were separated from fruit pulp. The pulp adhere to the seed was removed by washing. After washing the water was whips out from their surfaces with a piece of cleaned cloth and tissue paper. The seeds were then weighed and calculated as follow to determine the percent of seed composition as described by mazumdar and majumder (2003).

$$
\text { Percent seed }=\frac{\text { Weight of seed matter }(\mathrm{g})}{\text { Weight of whole fruit }(\mathrm{g})} \times 100
$$

\subsubsection{Determination of Peel (\%)}

Quince peel was determined through the method described by mazumdar and majumder (2003). In this regard the fruit was weighted first and the peel separated from fruit and weighed. The percent of peel was then calculated by the following formula

$$
\text { Percent peel }=\frac{\text { Weight of peel matter }(\mathrm{g})}{\text { Weight of whole fruit }(\mathrm{g})} \times 100
$$

\subsubsection{Determination of Edible Mater (\%)}

Quince edible matter was determined through the method described by mazumdar and majumder (2003).In this regard the fruit was weighted first. Fruit were cut to separate the non - consume able part (seed) from the consume able portion (pulp). The remaining portion adhere to the separated non consumable portion was brought back to the former part by careful scratching. Then the consumable matter was weighed. The percent of consumable matter was then calculated by the following formula

$$
\text { Percent peel }=\frac{\text { Weight of peel matter }(\mathrm{g})}{\text { Weight of whole fruit }(\mathrm{g})} \times 100
$$

\subsubsection{Sensory Evaluation}

The samples were tested and the overall acceptability (color, flavor, taste, and texture) of fresh samples were evaluated on a nine point hedonic scale according to larmond (1977) for sensorial assessment, quince fruits were served in clean transparent plates which had been labeled with random numbers. Questioners and water for mouth rising between each testing were provided prior to evaluation a session was held to familiarize with the products. Panelists were asked to read through the questionnaires and the meaning of each attribute was explained to the panelists to avoid any misinterpretation. Judges were not allowed to discuss their scores with one another during the evaluation session. The fruits then presented to the trained panel of sensory analysts. Another set of fruits were evaluated as replication by the next following dat. The sensory evaluation data were presented as means of the panelists score from $1-10$.

\subsubsection{Statistical Analysis}

The data were analyzed using 8.1 statistics software. The analysis of variance (ANOVA) tables was constructed using the generalized linear model (GLM) procedure. DPPH were expressed in percentages along with statistical standard deviation. The mean separations were carried out by the least significant difference (LSD) method at 1 and $5 \%$ significance level.

\section{Results and Discussion}

\subsection{Results}

Results of the main chemical composition, physical composition and sensory parameters of the two varieties of the Quince fruit are shown in tables 1 - 26 (where v1 is the sweet variety of Quince fruit and v2 is the sour variety of Quince fruit).

Table 1. Determination of moisture content (\%) of two varieties of Quince fruits.

\begin{tabular}{llllll}
\hline Varieties & Mean & Min & Max & S. D & CV \\
\hline V1 & Aa 84.56A & 84.20 & 84.90 & 0.35 & 0.41 \\
V2 & 84.36A & 84.10 & 84.60 & 0.25 & 0.29 \\
\hline
\end{tabular}

LSD: SEC: 0.2494; CTV: 2.776; CVC: 0.6926

- All the mean values are the result of three replications

- All the means carrying same alphabets are non significant at alpha $=0.05$

Table 2. Determination of Total Soluble Solids ( ${ }^{\circ}$ Brix) of two varieties of Quince fruits.

\begin{tabular}{llllll}
\hline Varieties & Mean & Min & Max & S. D & CV \\
\hline V1 & $1212.36 \mathrm{~A}$ & 12.30 & 12.40 & 0.05 & 0.46 \\
V2 & $10.73 \mathrm{~B}$ & 10.60 & 10.80 & 0.11 & 1.01 \\
\hline
\end{tabular}

LSD: SEC: 0.0745; CTV: 2.776; CVC: 0.2069

- All the mean values are the result of three replications

- All 2 means are significantly different from one another 
Table 3. Determination of Ash (\%) of two varieties of Quince fruits.

\begin{tabular}{llllll}
\hline Varieties & Mean & Min & Max & S. D & CV \\
\hline V1 & $3.36 \mathrm{~A}$ & 3.35 & 3.39 & 0.02 & 0.67 \\
V2 & 2.53B & 2.52 & 2.54 & 0.01 & 0.53 \\
\hline
\end{tabular}

LSD: SEC: 0.0153; CTV: 2.776; CVC: 0.0426

- All the mean values are the result of three replications

- All 2 means are significantly different from one another

Table 4. Determination of Total sugars (\%) of two varieties of Quince fruits.

\begin{tabular}{llllll}
\hline Varieties & Mean & Min & Max & S. D & CV \\
\hline V1 & $9.63 \mathrm{~A}$ & 9.50 & 9.80 & 0.15 & 1.58 \\
V2 & $9.06 \mathrm{~B}$ & 9.00 & 9.20 & 0.11 & 1.27 \\
\hline
\end{tabular}

LSD: SEC: 0.1106; CTV: 2.776; CVC: 0.3069

- All the mean values are the result of three replications

- All 2 means are significantly different from one another

Table 5. Determination of Reducing sugars (\%) of two varieties of Quince fruits.

\begin{tabular}{llllll}
\hline Varieties & Mean & Min & Max & S. D & CV \\
\hline V1 & $5.26 \mathrm{~A}$ & 5.20 & 5.40 & 0.11 & 2.19 \\
V2 & $5.06 \mathrm{~A}$ & 5.00 & 5.20 & 0.11 & 2.27 \\
\hline
\end{tabular}

LSD: SEC: 0.0943; CTV: 2.776; CVC: 0.2618

- All the mean values are the result of three replications

- All the means carrying same alphabets are non significant at alpha $=0.05$

Table 6. Determination of Non - reducing sugars (\%) of two varieties of Quince fruits.

\begin{tabular}{llllll}
\hline Varieties & Mean & Min & Max & S. D & CV \\
\hline V1 & $4.36 \mathrm{~A}$ & 4.20 & 4.60 & 0.20 & 4.76 \\
V2 & $4.00 \mathrm{~B}$ & 4.00 & 4.00 & 0.00 & 0.00 \\
\hline
\end{tabular}

LSD: SEC: 0.1202; CTV: 2.776; CVC: 0.3337

- All the mean values are the result of three replications

- All 2 means are significantly different from one another

Table 7. Determination of $p H$ of two varieties of Quince fruits.

\begin{tabular}{llllll}
\hline Varieties & Mean & Min & Max & S. D & CV \\
\hline V1 & $3.36 \mathrm{~A}$ & 3.30 & 3.40 & 0.06 & 1.71 \\
V2 & $3.39 \mathrm{~A}$ & 3.28 & 3.60 & 0.16 & 4.72 \\
\hline
\end{tabular}

LSD: SEC: 0.0335; CTV: 2.776; CVC: 0.0930

- All the mean values are the result of three replications

- All the means carrying same alphabets are non significant at alpha $=0.05$

Table 8. Determination Titratable acidity of two varieties of Quince fruits.

\begin{tabular}{llllll}
\hline Varieties & Mean & Min & Max & S. D & CV \\
\hline V1 & $1.33 \mathrm{~A}$ & 1.20 & 1.50 & 0.15 & 11.4 \\
V2 & $1.35 \mathrm{~A}$ & 1.16 & 1.50 & 0.17 & 12.9 \\
\hline
\end{tabular}

LSD: SEC: 0.1340; CTV: 2.776; CVC: 0.3720

- All the mean values are the result of three replications
- All carrying same alphabets are non - significant at alpha $=0.05$

Table 9. Determination of Ascorbic acid (mg/100g)of two varieties of Quince fruits.

\begin{tabular}{llllll}
\hline Varieties & Mean & Min & Max & S. D & CV \\
\hline V1 & $20.33 \mathrm{~A}$ & 20.00 & 21.00 & 0.57 & 2.83 \\
V2 & $23.66 \mathrm{~A}$ & 22.00 & 24.00 & 0.57 & 2.43 \\
\hline
\end{tabular}

LSD: SEC: 0.4714; CTV: 2.776; CVC: 1.3088

- All the mean values are the result of three replications

- All carrying same alphabets are non - significant at alpha $=0.05$ the means

Table 10. Determination of Total polyphenols compounds (mgGAE/100g) of two varieties of Quince fruits.

\begin{tabular}{|c|c|c|c|c|c|}
\hline Varieties & Mean & Min & $\operatorname{Max}$ & S. D & $\mathrm{CV}$ \\
\hline V1 & $\begin{array}{l}15 . \\
15.70 \mathrm{~A}\end{array}$ & 15.38 & 16.02 & 0.32 & 2.03 \\
\hline V2 & 7.77B & 7.56 & 7.98 & 0.21 & 2.70 \\
\hline
\end{tabular}

LSD: SEC: 0.2210; CTV: 2.776; CVC: 0.6135

- All the mean values are the result of three replications

- All 2 means are significantly different from one another

Table 11. Determination of Antioxidant activity of two varieties of Quince fruits.

\begin{tabular}{llllll}
\hline Varieties & Mean & Min & Max & S. D & CV \\
\hline V1 & $48.96 \mathrm{~A}$ & 46.91 & 48.05 & 0.58 & 1.24 \\
V2 & $47.39 \mathrm{~A}$ & 47.82 & 49.91 & 1.05 & 2.16 \\
\hline
\end{tabular}

LSD: SEC: 0.6996; CTV: 2.776; CVC: 1.9425

- All the mean values are the result of three replications

- All the means carrying same alphabets are non significant at alpha $=0.05$

\subsubsection{Physical Evaluation}

Table 12. Determination of Length ( $\mathrm{mm}$ ) of two varieties of Quince fruits.

\begin{tabular}{llllll}
\hline Varieties & Mean & Min & Max & S. D & CV \\
\hline V1 & $96.6 \mathrm{~A}$ & 90.0 & 110.0 & 25.1 & 29.0 \\
V2 & $86.6 \mathrm{~A}$ & 60.0 & 100.0 & 5.77 & 5.97 \\
\hline
\end{tabular}

LSD: SEC: 1.4907; CTV: 2.776; CVC: 4.1389

- All the mean values are the result of three replications

- All the means carrying same alphabets are non significant at alpha $=0.05$

Table 13. Determination of Width ( $\mathrm{mm}$ ) of two varieties of Quince fruits.

\begin{tabular}{llllll}
\hline Varieties & Mean & Min & Max & S. D & CV \\
\hline V1 & $90.0 \mathrm{~A}$ & 80.0 & 100.0 & 10.0 & 11.11 \\
V2 & $86.6 \mathrm{~A}$ & 70.0 & 100.0 & 15.2 & 17.62 \\
\hline
\end{tabular}

LSD: SEC: 1.0541; CTV: 2.776; CVC: 2.9266

- All the mean values are the result of three replications

- All the means carrying same alphabets are non significant at alpha $=0.05$ 
Table 14. Determination of Thickness (mm) of two varieties of Quince fruits.

\begin{tabular}{llllll}
\hline Varieties & Mean & Min & Max & S. D & CV \\
\hline V1 & $93.00 \mathrm{~A}$ & 83.00 & 103.00 & 59.9 & 10.7 \\
V2 & $89.66 \mathrm{~A}$ & 73.00 & 104.00 & 15.2 & 17.0 \\
\hline
\end{tabular}

LSD: SEC: 0.7630; CTV: 2.776; CVC: 2.1185

- All the mean values are the result of three replications

- All the means carrying same alphabets are non significant at alpha $=0.05$

Table 15. Determination of fruit Weight (g) of two varieties of Quince fruits.

\begin{tabular}{llllll}
\hline Varieties & Mean & Min & Max & S. D & CV \\
\hline V1 & $335.0 \mathrm{~A}$ & 269.0 & 386.0 & 59.92 & 17.88 \\
V2 & $293.3 \mathrm{~A}$ & 220.0 & 370.0 & 75.0 & 25.5 \\
\hline
\end{tabular}

LSD: SEC: 55.451; CTV: 2.776; CVC: 153.96

- All the mean values are the result of three replications

- All the means carrying same alphabets are non significant at alpha $=0$.

Table 16. Determination of Geometric Mean Diameter (mm) of two varieties of Quince fruits.

\begin{tabular}{llllll}
\hline Varieties & Mean & Min & Max & S. D & CV \\
\hline V1 & $83.33 \mathrm{~A}$ & 73.00 & 83.00 & 9.07 & 12.3 \\
V2 & $73.33 \mathrm{~A}$ & 65.00 & 92.00 & 9.60 & 11.5 \\
\hline
\end{tabular}

LSD: SEC: 0.7630; CTV: 2.776; CVC: 2.1185

- All the mean values are the result of three replications

- All the means carrying same alphabets are non significant at alpha $=0.05$

Table 17. Determination of Volume (cm3) of two varieties of Quince fruits.

\begin{tabular}{llllll}
\hline Varieties & Mean & Min & Max & S. D & CV \\
\hline V1 & 3328.53A & 326.80 & 330.20 & 1.70 & 10.7 \\
V2 & $285.40 \mathrm{~B}$ & 283.60 & 288.20 & 2.45 & 17.0 \\
\hline
\end{tabular}

LSD: SEC: 0.1700; CTV: 2.776; CVC: 0.4719

- All the mean values are the result of three replications

- All 2 means are significantly different from one another

Table 18. Determination of Sphericity (\%) of two varieties of Quince fruits.

\begin{tabular}{llllll}
\hline Varieties & Mean & Min & Max & S. D & CV \\
\hline V1 & $122.2 \mathrm{~A}$ & 120.00 & 124.40 & 2.20 & 10.7 \\
V2 & $103.71 \mathrm{~B}$ & 100.20 & 105.40 & 2.67 & 2.5 \\
\hline
\end{tabular}

LSD: SEC: 0.2404; CTV: 2.776; CVC: 0.6674

- All the mean values are the result of three replications

- All 2 means are significantly different from one another

Table 19. Determination of Pulp weight ( $g$ ) of two varieties of Quince fruits.

\begin{tabular}{llllll}
\hline Varieties & Mean & Min & Max & S. D & CV \\
\hline V1 & 331.0A & 263.0 & 383.0 & 61.57 & 18.60 \\
V2 & 289.3A & 216.0 & 366.0 & 75.08 & 25.97 \\
\hline
\end{tabular}

LSD: SEC: 55.451; CTV: 2.776; CVC: 153.96
- All the mean values are the result of three replications

- All the means carrying same alphabets are non significant at alpha $=0.05$

Table 20. Determination of Edible portion (\%) of two varieties of Quince fruits.

\begin{tabular}{llllll}
\hline Varieties & Mean & Min & Max & S. D & CV \\
\hline V1 & $90.56 \mathrm{~A}$ & 90.30 & 90.90 & 0.30 & 0.33 \\
V2 & $90.76 \mathrm{~A}$ & 90.60 & 90.90 & 0.15 & 0.16 \\
\hline
\end{tabular}

LSD: SEC: 0.1972; CTV: 2.776; CVC: 0.5475

- All the mean values are the result of three replications

- All the means carrying same alphabets are non significant at alpha $=0.05$

Table 21. Determination of Peel (\%) of two varieties of Quince fruits.

\begin{tabular}{llllll}
\hline Varieties & Mean & Min & Max & S. D & CV \\
\hline V1 & $4.50 \mathrm{~A}$ & 4.20 & 4.70 & 0.26 & 5.8 \\
V2 & $4.66 \mathrm{~A}$ & 4.30 & 4.90 & 0.32 & 6.88 \\
\hline
\end{tabular}

LSD: SEC: 0.2404; CTV: 2.776; CVC: 0.6674

- All the mean values are the result of three replications

- All the means carrying same alphabets are non significant at alpha $=0.05$

Table 22. Determination of Seed (\%) of two varieties of Quince fruits.

\begin{tabular}{llllll}
\hline Varieties & Mean & Min & Max & S. D & CV \\
\hline V1 & $5.23 \mathrm{~A}$ & 5.00 & 5.50 & 0.25 & 4.80 \\
V2 & $5.26 \mathrm{~A}$ & 5.10 & 5.40 & 0.15 & 2.90 \\
\hline
\end{tabular}

LSD: SEC: 0.1700; CTV: 2.776; CVC: 0.4719

- All the mean values are the result of three replications

- All the means carrying same alphabets are non significant at alpha $=0.05$

\subsubsection{Sensory Evaluation}

Table 23. Determination of Taste level of two varieties of Quince fruits.

\begin{tabular}{llllll}
\hline Varieties & Mean & Min & Max & S. D & CV \\
\hline V1 & $7.33 \mathrm{~A}$ & 7.20 & 7.50 & 0.15 & 2.08 \\
V2 & $6.23 \mathrm{~B}$ & 6.10 & 6.40 & 0.15 & 2.45 \\
\hline
\end{tabular}

LSD: SEC: 0.2210; CTV: 2.776; CVC: 0.6135

- All the mean values are the result of three replications

- All 2 means are significantly different from one another

Table 24. Determination of Color level of two varieties of Quince fruits.

\begin{tabular}{llllll}
\hline Varieties & Mean & Min & Max & S. D & CV \\
\hline V1 & $7.40 \mathrm{~A}$ & 7.20 & 7.60 & 0.20 & 2.70 \\
V2 & $7.23 \mathrm{~A}$ & 7.10 & 7.40 & 0.15 & 2.11 \\
\hline
\end{tabular}

LSD: SEC: 0.0745; CTV: 2.776; CVC: 0.2069

- All the mean values are the result of three replications

- All the means carrying same alphabets are non significant at alpha $=0.05$ 
Table 25. Determination of Flavor level of two varieties of Quince fruits.

\begin{tabular}{llllll}
\hline Varieties & Mean & Min & Max & S. D & CV \\
\hline V1 & $8.26 \mathrm{~A}$ & 8.00 & 8.60 & 0.30 & 3.69 \\
V2 & $7.26 \mathrm{~B}$ & 7.00 & 7.60 & 0.30 & 4.20 \\
\hline
\end{tabular}

LSD: SEC: 0.0153; CTV: 2.776; CVC: 0.0426

- All the mean values are the result of three replications

- All 2 means are significantly different from one another

Table 26. Determination of Overall acceptability of two varieties of Quince fruits.

\begin{tabular}{llllll}
\hline Varieties & Mean & Min & Max & S. D & CV \\
\hline V1 & $8.36 \mathrm{~A}$ & 8.10 & 8.60 & 0.25 & 3.00 \\
V2 & $7.166 \mathrm{~B}$ & 7.00 & 7.40 & 0.20 & 2.90 \\
\hline
\end{tabular}

LSD: SEC: 0.1213; CTV: 2.776; CVC: 0.3369

- All the mean values are the result of three replications

- All 2 means are significantly different from one another

\subsection{Discussion}

In the present study the standard physical, chemical and sensory parameters of two varieties of Quince fruit were studied. Physicochemical attributes play an important role in determining the nature and behavior of the fruit and their response to handling and processing. These attributes are very important to horticulturists, engineers and food technologists who together seek to developed satisfactory harvesting, handling and processing technologies (Xie and Zhao, 2004). The morphological parameters include in this study are fruit thickness, volume, weight, sphericity, geometric mean diameter, length, width, pulp weight, taste, color, flavor and overall acceptability. Some other scientists have also legitimate the above mentioned parameters as physico - chemical characteristics of fruits. For example (Owolareafe and Shotonde, 2004; kashaninejedet al, 2006; Bart - Plange Baryeh, 2003). Shape, size, density, color, pH, ascorbic acid, titratable acidity and antioxidant activity play a vital role in the design of harvesting and processing equipment and techniques (Liang et al., 1991).

Present study is carried out on the two varieties of Quince fruits i.e. sweet variety (v1) and sour variety (v2). The sweet variety was found superior then the sour variety on the basis of these findings, in terms of nearly all physical chemical and sensory parameters. Regarding length, width, thickness, fruit and pulp weight, geometric mean diameter, seed portion, peel portion and edible portion our findings reached to a reliable conclusion that there is slightly or no difference among the varieties. These remarks are in agreement with the findings of (Sharma et al., 2011). The volume and sphericity among the varieties is slightly different. The color, taste, flavor and overall acceptability were also examined in this study. It may be concluded on judges remarks that variety (V1)has got better sensory attributes as compared to variety (v2) sour Quince.

Other chemical parameters such as Total soluble solids, ash content, sugars (total, reducing and non - reducing), total phenolics, ascorbic acid, $\mathrm{pH}$, moisture content, antioxidants and Titratable acidity were also analyzed. In the current study the moisture content was recorded from $84.1 \%$ in to $84.9 \%$ in the fruit varieties. The results of current study are nearly similar to those showed by Yugoslavian and Indian Quince cultivars (Sharma et al., 2011). The evaluation of total soluble solids content (TSS) showed significant differences among clones and values ranged from (10.6 ${ }^{\circ}$ Brix) to (12.4 ${ }^{\circ}$ Brix) clones had significantly lower contents of TSS than those previously reported by other authors (Sharma et al., 2011; Ercisli et al., 1999)which were around 15 Brix, but they were similar to those reported by (Legua et al., (2013).

The results showed that significantly highest ash content was found in the sweet variety $(3.39 \%)$ followed by sour variety $(2.54 \%)$. These varieties had significantly higher ash contents than those previously reported by (Hegedus et al., 2011) which was around $0.6 \%$. However variations among fruit varieties and locations might be due to differences in plant genotype, orchard, soil conditions and environmental factors, as it was earlier studied by (Morais et al., 2001) and (Francket al., 2003a).The sugar profile of fruits is a significant constituent of chemical composition tables and provides important information concerning the authenticity of fruit juices and individual sugar and total sugars correlated well with the sweetness distinctiveness of the fruit juice, based on sensory evaluation. Sugars are also an instantaneous source of energy. Quince fruit contains considerable amounts of sugars. Results regarding the sugars are in line with the earlier studies of (Sharma et al., 2011) who reported total sugars in different Quince cultivars ranging from 8.4 to $9.8 \%$.

$\mathrm{pH}$ variation was very small, and ranged within the limits 3.3 and 3.4 no statistically significant differences were found among clones. The $\mathrm{pH}$ values found in the present study agreed well with previously reported by (Rodríguez Guisado et al., 2009; Ercisli et al., 1999). However, (Yarlgac, 2001) obtained higher value 6.65 that is far above those yielded by the Spanish ones.The variation of $\mathrm{pH}$ in Quince fruits could be result of cultivars and the effect of different environmental conditions where the cultivars grown. Wide variations in physicochemical properties have been reported among cultivars of different fruit species, such as peach (Moriguchi et al., 1990) and strawberry (Ngo et al., 2007).

The content of titratable acidity of fruits is an important quality parameter and a key determinant of fruit taste. It also serves as food substance and need by the body in little amounts. The results substantiated that the titratable acidity was found be equal in both varieties (1.50) each.The results of recent study regarding titratable acidity are in accordance with the findings of (Sharma etal., 2011). Who reported titratable acidity in Quince fruit ranging from 1.2 to $2.0 \%$.

Ascorbic acid is of great importance due to its several roles in the human body. In humans it has been associated with the prevention of chronic diseases. It is recognized as an important antioxidant and a quality sign of post - harvest shelf life of fruits and vegetables (Davey et al., 2000). The results showed that significantly highest ascorbic acid content was recorded in sour variety of Quince fruit samples 
(24 mg/100 g) followed by sweet variety of Quince fruit samples $(21 \mathrm{mg} / 100 \mathrm{~g})$ which were statistically different. The findings of ascorbic acid content of the current study are very low as compared by the finding of (ROP et al., 2011) who previously analyzed different varieties of Quince fruit for ascorbic acid content and results were in range of 41.12 to $79.15 \mathrm{mg} / 100 \mathrm{~g}$. While the findings of current study are well supported by the finding of (Sharma et al., 2011) who reported ascorbic acid in Quince fruit ranging from 16.8 to $17.6 \mathrm{mg} / 100 \mathrm{~g}$. The concentration of ascorbic acid can be influenced by various factors such as variety, climatic conditions, harvest practices, storage conditions and processing technologies (Lee and Kader, 2000). Difference among Quince varieties used in this study for ascorbic acid content might be due to above factors.

The bioactive compounds that play an important role in the plant resistance mechanism and also in expression of antioxidants in plant are Phenolics (Usenik et al., 2004). They have protective roles against coronary heart diseases (Hollman et al., 1996) and also play a key role in the adulteration control of foods (Sontag and Bernwieser, 1994).The results showed that significantly highest total phenolic content in sweet variety of Quince fruit (16.02 mg GAE/100g) followed by sour variety of Quince fruit (7.98 $\mathrm{mg}$ GAE $/ 100 \mathrm{~g}$ ). The findings of total phenolic content of current study are very low as compared by the finding of (Fattouch et al., 2007) who previously analyzed different varieties of Quince fruit for total phenolic content and results were in range of, 42 and $131 \mathrm{mg} 100 \mathrm{~g}-1$ of fw in Quince pulp and peel, respectively.The significant differences regarding total phenolics among fruit varieties and locations might be due to variation in plant genotypes, soil conditions, harvest practices, storage conditions and processing technologies as earlier reported (Lee and Kader, 2000).

Antioxidants are substances that can prevent or delay oxidative damage of proteins, lipids and nucleic acids by reactive oxygen groups such as free radicals. They scavenge radicals by inhibiting initiation and breaking chain propagation or suppressing formation of free radicals by binding to the metal ions, reducing hydrogen peroxide and quenching superoxide and singlet oxygen (Shi et al., 2001).The results revealed that significantly highest antioxidant activity was found in sour variety of Quince fruit (49.91\%) followed by sweet variety of Quince fruit (48.05\%). Quince varieties used in current study has shown higher antioxidant activity as compared to other fruits and it was previously studied by (Reza and Khadijeh H. 2014). Variation among fruit cultivars and locations regarding antioxidant activity might be due differences in plant genotype, orchid, soil conditions and environmental factors, as it was earlier studied by (Morais et al., 2001) and (Franck et al., 2003a) for antioxidants in fruits.

\section{Conclusion}

There has been an increasing interest for the inclusion of fresh fruits and vegetables in the human diet for the health benefits associated with their use. A major benefit from a higher consumption of fruits provide increased consumption of vitamins such as vitamin $\mathrm{C}$, vitamin A, vitamin B6, thiamin and niacin, minerals and dietary fiber. Other constituents such as antioxidant compounds, carotenoids, flavonoids and phenolics that may lower the risk of cancer and heart disease as well as prevent degenerative diseases are also found in fruits. There is considerable evidence for the role of antioxidant constituents of fruits in the maintenance of health and the prevention of disease.

\section{Acknowledgement}

Authors wish acknowledge all contributors who give their input during the research period and special thanks Department of Agriculture and Food Technology, Karakoram International University, Gilgit, Pakistan.

\section{References}

[1] AOAC. 1990. Official Methods of Analysis. Association of Analytical Chemist. (15th Ed.) Virginia, 22201, Arlington, USA. Food Chem., 72: 419 - 424.

[2] AOAC. 2000. Official Methods of Analysis. Association of Analytical Chemist. (18th Ed.) Virginia, 22201, Arlington, USA. Food Chem., 72: 415 - 428.

[3] Biro Gy. \& Lindner K. (1999): Tápanyagtáblázat. Medicina, Budapest.

[4] FAO, 2010. Statistical database, <http: //faostat. fao. org > Accessed 15.01.10.

[5] Hamauzu, Y., Inno, T., Kume, C., Irie, M. \& Hiramatsu, K. (2006): Antioxidant and antiulcerative properties of phenolics from Chinese quince, quince, and apple fruits. J. Agr. Food Chem., 54: 765-772.

[6] Hamid R. G., Khadijeh. H. A., 2014. Drying method effect on the antioxidant of quince (cydonia oblonga miller) Tea. Acta Sci. Pol., Technol. Aliment. 13 (2)129 - 134.

[7] Karacali, I. 1990. The storage and handling of horticultural crops. Ege. University Agricultural Faculty, Turkey. p. 413.

[8] Kawamura, T. 2000. Relationship between skin, color and maturity of Japanese pear 'Housui'. Jap. J. Farm. Work Res., $35: 33-38$.

[9] Liang, M., L. H. Chen and J. R. Hegwood. 1991. Physical and mechanical properties of muscadine grapes. Tech. Bulletin Mississippi Agric. Forestry Exper. Station., 176: 1 - 22.

[10] Marina, F.; Escalada, P.; Morena, U.; Eliana, N. F.; Lia, N. G.; Ana, M. R. Influence of the isolation procedure on the characteristics of fiber - rich products obtained from quince wastes. Journal of Food Engineering 2010, 96, 239-248.

[11] Madi R, Szabo T and Brozik S (1996). Renewed assortment of Quince varieties in Hungary. Horticultural Science 2826 - 31.

[12] McCabe, C. (1996) Enjoying the forbidden fruit. Saveur 14: 105-110. USDA. 2009b. National Agricultural Statistics Service, U.S. fruit production data. http: //www. nass. usda. gov/Qui ckStats/i ndexbysubject. jsp (accessed 4 jaunry, 2015). 
[13] Przemysław, J. s., S. M. Picazo., A. Szumny., A. A. Carbonell - Barrachina., and F. Hernández 2014. Quality parameters, bio - compounds, antioxidant activity and sensory attributes of Spanish quinces (Cydonia oblonga Miller). J. Scientia Horticulturae 165: 163-170.

[14] Rasoulzadegan I (1991). Pomologycal at temperate regions. Sanati university of Isfahan press, Sharma, R., Joshi, V. K., Rana, J. C., 2011. Nutritional composition and processed products of quince (Cydonia oblonga Mill.). Indian J. Nat. Prod. Resour. 2, 354-357.

[15] Rodriguez - Guisado I., Hernandez F., Melgarejo P., Legua P., Martinez R., Martinez J. J., 2009. Chemical, morphological and organo leptical characterisation of five Spanish quince tree clones (Cydonia oblonga Miller). Sci. Hortic. 122, 491 496.

[16] Rop, O., Balik, J., Řezniček, V., Jurikova, T., Škardova, P., Salaš, P., Sochor, J., Mlček, J. \& Kramařova, D. (2011): Chemical characteristics of fruits of some selected quince
(Cydonia oblonga Mill.) cultivars. Czech J. Food Sci., 29: 65-73.

[17] Shinomiya, F., Hamauzu, Y., Kawahara, T., 2009. Anti allergic effect of a hot extract of quince (Cydonia oblonga). Biosci. Biotechnol. Biochem 73, 1773-1778.

[18] Silva, B. M., Andrade, P. B., Mendes, G. C., Seabra, R. M., Ferreira, M. A., 2002. Study ofthe organic acids composition of quince (Cydonia oblonga Miller) fruit and jam. J. Agric. Food Chem. 50, 2313-2317765.

[19] Wallis, T. E., Textbook of pharmacognosy, CBS publishers \& distributors, New Delhi, 2005, 219 - 220.

[20] Xie, J. and Y. Zhao. 2004. Physical and physicochemical characteristics of three U.S. strawberry cultivars grown in the Pacific Northwest J. Food Qual., 27: 181 - 194.

[21] Zargari A. 1986. Medicinal plants. 4th ed. Tehran: Tehran University Publications. p. 243 - 246. 